Physiol Behav. 2014 June 22; 133: 61-67. doi:10.1016/j.physbeh.2014.05.004.

\title{
Cortisol and Politics: Variance in Voting Behavior is Predicted by Baseline Cortisol Levels
}

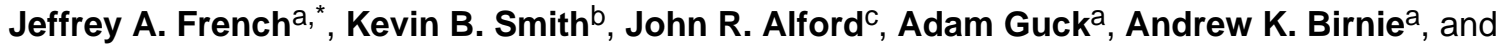 \\ John R. Hibbing ${ }^{b}$ \\ aDepartment of Psychology, University of Nebraska at Omaha, 6001 Dodge Street, Omaha NE \\ 68182, USA \\ ${ }^{b}$ Department of Political Science, University of Nebraska-Lincoln, 1400 R Street, Lincoln NE \\ 68588, USA \\ 'Department of Political Science, Rice University, 6100 Main Street, Houston, Texas 77005, USA
}

\begin{abstract}
Participation in electoral politics is affected by a host of social and demographics variables, but there is growing evidence that biological predispositions may also play a role in behavior related to political involvement. We examined the role of individual variation in hypothalamic-pituitaryadrenal (HPA) stress axis parameters in explaining differences in self-reported and actual participation in political activities. Self-reported political activity, religious participation, and verified voting activity in U.S. national elections were collected from 105 participants, who were subsequently exposed to a standardized (nonpolitical) psychosocial stressor. We demonstrated that lower baseline salivary cortisol in the late afternoon was significantly associated with increased actual voting frequency in six national elections, but not with self-reported non-voting political activity. Baseline cortisol predicted significant variation in voting behavior above and beyond variation accounted for by traditional demographic variables (particularly age of participant in our sample). Participation in religious activity was weakly (and negatively) associated with baseline cortisol. Our results suggest that HPA-mediated characteristics of social, cognitive, and emotional processes may exert an influence on a trait as complex as voting behavior, and that cortisol is a better predictor of actual voting behavior, as opposed to self-reported political activity.
\end{abstract}

\section{Keywords}

Cortisol; Stress; Politics; Voting behavior

(C) 2014 Elsevier Inc. All rights reserved.

*To Whom Correspondence Should be Addressed: Jeffrey A. French, Department of Psychology, University of Nebraska at Omaha, Omaha NE 68182, jfrench@unomaha.edu, PHN: 402-554-2558, FAX: 402-554-3121.

Supplementary Information for this article can be found online at http://

The authors declare no conflicts of interest relative to the data contained in this paper.

Publisher's Disclaimer: This is a PDF file of an unedited manuscript that has been accepted for publication. As a service to our customers we are providing this early version of the manuscript. The manuscript will undergo copyediting, typesetting, and review of the resulting proof before it is published in its final citable form. Please note that during the production process errors may be discovered which could affect the content, and all legal disclaimers that apply to the journal pertain. 


\section{Introduction}

Traditional explanations of variation in political temperament and behavior focus on demographics, parental socialization, resources, motivation, and personality, including age, sex, income, education, rational self-interest, altruism, conscientiousness, and openness to new experiences [1-6]. In addition to these demographic and sociocultural factors, increasing attention has also been given to the role of genetics $[3,4,7,8]$. Whatever their original sources, at some point the factors that shape temperament and behavior must operate through biological states, since perception, processing, and responding all entail physiological actions. Physiology is thus a potentially valuable marker for political phenotypes. Despite urgings dating at least to the $4^{\text {th }}$ Century B.C. (Aristotle), few studies have systematically examined the physiological correlates of political temperament and behavior.

Research has reported that differences in political ideology (e.g., liberal/conservative; left/ right) or differences in salient issue positions (e.g., support or opposition to gay marriage, the death penalty, and illegal immigrants) correlate with brain anatomy [9], brain activation patterns in response to an unexpected stimulus [10], and electrodermal activity in response to negative stimuli $[11,12]$. Yet, interesting as ideological positions may be, people's political temperaments consist of much more than these traits. Of particular interest here is variation in people's involvement in various aspects of the political process, ranging from contributing time and/or money to political events, campaigns, and other activities to ultimately exercising the vote on Election Day. In fact, a perennial concern of many modern democracies is insufficient public participation in the political sphere [13]. Progress on this vexing issue requires better understanding of both the short-term and long-term correlates of political participation.

A host of short-term environmental events influence political involvement, including voterparticipation campaigns and particularly stimulating or controversial electoral contests $[14,15]$. However, it is equally clear that these occasional alterations take place against the backdrop of long-term, individual-level consistency. Whether the target variable is political participation [14,16,17], political attitudes [18] or levels of political interest [19] both interperson variability and intra-person stability are apparent, though the reasons for this stability are not. Conditions and traits, such as age, education, and income [1,20] all correlate positively with political participation and are relatively stable over time but the mechanisms by which they connect to participatory acts are largely unspecified. In a parallel fashion, many physiological traits demonstrate inter-person variability and intra-individual stability [21,22], raising the possibility that there may be value in testing for the correlation of political involvement and physiological measures.

An intriguing potential source of variation in political involvement is individual differences in functioning in the neuroendocrine stress system, the hypothalamic-pituitary-adrenal (HPA) axis. Both basal and stress-reactive components of this axis, assessed by monitoring cortisol (CORT) production, are shaped by multiple factors [2]. A growing list of candidate genes shows polymorphisms that map onto differences in basal CORT levels and CORT reactivity to stressors [24,25], and these and other genes interact with early social and 
physical environments $[26,27]$ to ultimately determine stress-response styles. It is also wellestablished that variation in function in the HPA axis is associated with differences in social, emotional/affective, and decision-making processes in both nonclinical [28-30] and clinical [31,32] populations. Given that political participation likely involves a complex combination of psychological factors that are associated with HPA activity, variation in HPA function may be predictive of the relatively stable individual differences in political involvement. Several studies have addressed the consequences of political participation on subsequent cortisol levels, demonstrating that cortisol levels are higher on election days than on nonelection days [33], that cortisol levels in supporters of losing candidates are elevated relative to cortisol levels in supporters of winning candidates [34], and that highly politically-partisan participants exhibit elevated cortisol after reading a post-election political essay, relative to reading a nonpolitical text passage [35]. To our knowledge, however, the notion that individual differences in the fundamental operating characteristics of the HPA axis are correlated with, and hence may be causally related to variation in the likelihood of engaging in political activity, has not been tested.

We tested the association between HPA function and political involvement in a representatively-selected population of eligible voters. HPA axis function was assessed by exposing participants to a standardized psychosocial stressor (Trier Social Stress Test (TSST): [36,37], and both baseline and stress-reactive components of HPA activity were assessed by measuring levels of salivary cortisol. Political participation was assessed in two ways: (1) self-reported involvement with political matters; and (2) actual records of voting in six national-level elections (primary and general elections of 2006, 2008, and 2010). For comparison purposes, we also measured participants' involvement in a social but nonpolitical organized activity (religious participation). Given that politics by its nature entails conflict and social stress, we expected that baseline and reactive CORT levels would be inversely related to individual-level variations in political involvement.

\section{Methods}

\subsection{Participants and Survey Instruments}

We retained the services of a professional survey research organization to assist in the recruitment of participants. Employees of this organization contacted by phone (a statistically appropriate mix of landlines and cellphones) a random sample of adults within easy driving distance of our laboratory in a medium-sized city in the Midwest United States. Specifically, individuals contacted were asked if they would be willing to report to the lab to complete a comprehensive computer survey of their sociodemographics, political orientations, and personality tendencies, in addition to completing baseline cognitive and physiological tests. We recruited 345 individuals in this fashion. Our sample is not a student-based one, and was reasonably representative of the geographical area from which it was drawn. All procedures with human participants were reviewed and approved by the Institutional Review Board at the University of Nebraska, Lincoln, and all participants provided informed consent prior to participating in any collection of data.

We selected a smaller sample $(n=105)$ from the original sample for evaluation of HPA function. In order to insure representative variation in political ideology in the subsample 
assessed for HPA function, we used the answers provided in the survey administered during their first visit to the lab to identify participants from the group of 345 who scored highest on three measures of ideology: political conservatism, political liberalism, and political disinterest. Because our primary interests were in accounting for variation in voting behavior and not political ideology or party affiliation, we recruited participants equally from these three groups for the assessment of HPA function, proceeding into the middle of the distributions as necessary. These procedures yielded a subsample similar to the full sample (detailed demographic information on the subsample can be found in Supplemental Information: Table S1).

\subsection{Stress protocol}

In order to minimize the effects of diurnal variation and to increase participation from our nonstudent population, selected participants reported to the laboratory at one of two testing times in the late afternoon: 1700 or $1800 \mathrm{~h}$. Also, to minimize the effects of seasonal variations in CORT, all testing was done within a two-week period. Participants were asked to refrain from eating or drinking for two hours prior to reporting for the study. After completing informed consent, participants provided a passive drool saliva sample via a $4 \mathrm{~cm}$ length of plastic straw directly into a $1.5 \mathrm{ml}$ microcentrifuge tube: this sample was used to establish baseline CORT (Time $=0 \mathrm{~min}$ ). All participants were then exposed to a modified TSST procedure for groups [38]. In a context designed to produce social/evaluative stress, groups of participants $(n=3-8$ per cohort) spent 10 min preparing a speech for a job interview. Props in the experimental room suggested that the speech would be videotaped and participants were told that expert evaluators both present in the room and via remote video connection would evaluate their performance. Following this, participants were asked to conduct complex mental arithmetic out loud for $5 \mathrm{~min}$ in front of an evaluator (subtracting by 17's, starting at 1,020) and were asked to begin again if they made a mistake. In contrast to von Dawans et al. [38], our participants did not actually perform the speech and they were informed of this at the completion of the mental arithmetic. There is good reason to suspect that the anticipation of public speaking and the attendant potential for negative social evaluation is sufficient to elicit elevated CORT responses independent of actually delivering the speech [37], and the results in Figure 1 suggest this is in fact the case. A second saliva sample was collected at the completion of the mental arithmetic task (15 min). Participants then were moved to a neutral room and asked to watch a 60-min videotape (a tourism film with bucolic scenes of traveling and vacationing in northern England). During the film, additional saliva samples were collected at 20,30, 45, 60, and $75 \mathrm{~min}$ from the collection of the first sample.

\subsection{Salivary cortisol assays}

After completion of the 75 -min procedure, saliva samples were frozen and stored at $-23^{\circ} \mathrm{C}$. All endocrine procedures were conducted in the Endocrine Bioservices Laboratory at the University of Nebraska at Omaha. After centrifugation, samples were assayed for cortisol concentration by enzyme immunoassay (EIA). The CORT EIA has previously been described in detail [39]. Duplicate CORT values that varied by more than 5\% were reassayed. A quality control sample of pooled saliva was assayed on each plate, and the intra- and interassay coefficients of variation were $7.6 \%$ and $17.3 \%$, respectively. The 
biological validity of the salivary CORT assay for human samples has been previously demonstrated [40]. Initial assays comparing standard cortisol concentrations and serial dilutions of the saliva pool produced parallel displacement curves, demonstrating immunological validity for salivary cortisol. All samples from an individual subject were assayed on the same plate to further minimize procedural variance. Further details on the protocol, reagents, and quality control can be found in Supplemental Information: Methods).

Several measures were derived from the CORT values, including maximum CORT, change in CORT, AUC-Increase and AUC-Ground $\left(\mathrm{AUC}_{\mathrm{I}}\right.$ and $\mathrm{AUC}_{\mathrm{G}}$, respectively; [41], and regulation of the CORT response (CORT concentration at $75 \mathrm{~min}$ - baseline CORT). We limited our analyses in this paper to two fundamental properties of HPA function: baseline CORT and $\mathrm{AUC}_{\mathrm{I}}$, a measure of HPA set-point and an integrated index of stress reactivity that minimizes the influence of individual differences in baseline CORT in assessing reactivity to stressors, respectively.

\subsection{Analysis}

Two central political variables were computed: voting frequency and non-voting participation. Voting frequency was computed by summing the number of times each participant voted from $2006-2010$ (range $=0$ to 6 ). These data were obtained from the relevant office of the Secretary of State, and reflect an accurate measure of behavioral participation in the electoral process. Non-voting participation was computed by summing each participant's answers on five dichotomous yes/no items (1=no, 2=yes) that included whether the participant had attended a political meeting or rally, sent a message to a public official, worked for a political campaign in any capacity, run for any office, however minor, and donated money to a political cause or campaign, and on one 4-choice item that evaluated the frequency at which participants engaged in political discussions with others (1=never, $4=$ very often; collapsed to a 1-2 range so that all items were weighted equally). Finally, we asked participants to report participation in religious activities ("How often do you go to church?"), scored on a four-point scale ranging from "Never" to "More than once per week").

Pearson's bivariate correlations were calculated among CORT variables (baseline and $\mathrm{AUC}_{\mathrm{I}}$ ), political variables, and religious participation. Hierarchical regressions were then conducted to test the hypothesis that HPA function is related to voting frequency, nonvoting political participation, and religious participation. We limited the physiological predictors of these dependent variables to baseline CORT and $\mathrm{AUC}_{\mathrm{I}}$ (measures of HPA setpoints and HPA reactivity, respectively) to minimize the impact of multicolinearity of the physiological variables. We ran three models: Model 1 included only the four demographic variables (age, sex, education, and income), Model 2 added baseline CORT, and Model 3 included $\mathrm{AUC}_{\mathrm{I}}$. Effect sizes $\left(f^{2}\right)$ in the hierarchical regression for the added variables in Models 2 and 3 were determined according to the methods characterized by Cohen [42], with $f^{2}<0.05=$ small effect, $0.05-0.10=$ small to moderate effect, and $>0.10=$ large effect. For illustrative purposes, we also divided subjects into quartile groups on the basis of baseline CORT ( $n=26$ or 27 per quartile) and conducted ANCOVA on political participation and religious outcome variables (using our four demographic variables as 
covariates) to test for mean differences among participants in the four quartiles on our measures of political and religious involvement. All analyses were two-tailed and the criterion for statistical significance was set at $p \leq .05$.

\section{Results}

Our sample consisted of 105 participants who were selected from a larger random sample $(\mathrm{N}=345)$ that was representative of the geographical area of the country from which it was drawn (demographics of sample in Supplemental Information: Table S1). Voting behavior varied across participants, and ranged from $0-6$ votes in the six elections. A plurality of participants $(n=28)$ voted in all elections, five voted in no elections, and at least ten participants were included in all other categories of voting frequency. No CORT measures varied as a function of group size during stress assessment or as a function of time of testing (see Materials and Methods). Scales of self-reported involvement in political activity and organized religious activity were normally distributed and ranged between the extreme possible scores for these measures.

\subsection{Cortisol and Political Participation}

Overall, participants exhibited an increase in salivary CORT levels in response to the modified TSST (Figure 1). Mean CORT levels rose steadily and peaked at the 45-minute sampling interval and then declined at the 60- and 75-minute sampling intervals.

CORT levels differed significantly among time points $\left(F_{6,624}=5.48, p<0.001\right)$ and were significantly higher than the pre-TSST measure (hereafter "baseline CORT") at all timepoints after the 15-min stress-induction protocol, and lower at the final 75-min samples than levels at 45- and 60-min of the TSST. Thus, our modified TSST protocol was effective in eliciting temporary elevations in CORT levels across participants.

Bivariate Pearson's correlations between the baseline and stress-reactive CORT and the various measures of political involvement are displayed in Table 1 .

As might be expected, the measures of salivary CORT were negatively correlated with one another: participants with high baseline CORT showed lower $\mathrm{AUC}_{\mathrm{I}}$ scores throughout the TSST protocol. Measures of voting frequency positively correlated with self-reported nonvoting political activity. Participation in organized religious activity was not correlated with measures of baseline and stress-induced CORT, and variation in participation in religion did not correlate significantly with individual differences in participation in elections or self-reported political activities.

In separate hierarchical regression models, we employed voting frequency, nonvoting participation, and religious participation as criterion variables, and included a standard array of demographic controls (education, gender, age, and income), along with baseline CORT and Area Under the Curve-Increase $\left(\mathrm{AUC}_{\mathrm{I}}\right)$ as predictor variables. In bivariate analyses, these demographic variables predicted political involvement in the fashion suggested in the literature [17]. Given voting's status as the quintessential form of political participation, hierarchical regression results for voting frequency are presented in Table 2 . When only the 
four demographic variables are included in the hierarchical regression (Model 1), the model significantly predicted variation in Voting frequency as a whole, but age was the only significant individual variable that predicted voting frequency (older participants voted more often than younger participants). Adding baseline CORT to the hierarchical regression (Model 2) significantly enhanced the prediction of voting frequency: participants with higher baseline CORT were less likely to vote, even while controlling for demographic variables $\left(F \Delta_{1,99}=6.90, p<0.01\right)$. The effect size $\left(\right.$ Cohen's $\left.f^{2}\right)$ is 0.07 after the addition of baseline CORT to the hierarchical regression model. In contrast, the inclusion of a composite measure of stress reactivity $\left(\mathrm{AUC}_{\mathrm{I}}\right)$ did not significantly improve prediction of voting behavior beyond baseline CORT (Model 3). To further illustrate the relationship between baseline CORT and voting frequency, we divided participants into quartiles according to their baseline CORT and computed the mean for Voting frequency for each quartile. As can be seen in Figure 2a, voting frequency differed significantly across participants with differing baseline CORT $\left(F_{3,101}\right)=5.98$. $\left.p<0.001\right)$, even after controlling via ANCOVA for predictive demographic variables. Mean voting frequency was highest in participants in the lowest quartile of baseline CORT, and dropped sharply in participants in the highest quartile.

With regard to non-voting participation, Model 1 regressions (demographic variables) significantly predicted variation in these scores, and again revealed that age was positively and significantly associated with these measures (see Table 3). Unlike voting frequency, however, neither baseline CORT (Model 2) nor $\mathrm{AUC}_{\mathrm{I}}$ (Model 3) increased predictive ability for non-voting participation, suggesting important differences in the links between stress physiology and voting frequency on the one hand and stress physiology and nonvoting political activity on the other. Confirming these findings, non-voting participation did not differ significantly across groups derived from baseline CORT quartiles (ANCOVA: $p>$ 0.20; Fig. 2b).

\subsection{Cortisol and Religious Activity}

Importantly, and in contrast to voting frequency, variation in participation in religious activity was not significantly associated with age, education, sex, or income (although participants with higher incomes tended to be more involved in religious activity; $p=0.08$ ). Adding baseline CORT and AUCI to the regression models did not significantly enhance prediction of self-reported religious activity (Supplemental Information: Table S3). However, ANCOVA analyses revealed that church attendance did vary in a bivariate sense as a function of quartile baseline CORT $\left(F_{3,101}=2.52, p<0.03\right)$, and post-hoc tests revealed that participants with low and moderately-low baseline CORT had higher church attendance scores $(2.53 \pm 0.12)$ than participants with moderately-high and high baseline CORT $(2.21 \pm$ $0.13 ; p<0.01$; Fig. 2c). Thus, when standard controls are included, the relationship we demonstrated between voting participation and baseline CORT do not generalize to at least one other measure of activity in organized social involvement, church attendance.

\section{Discussion}

Adequate levels of political participation are a prerequisite for a viable democracy, yet in the most recent presidential elections in the United States approximately 93 million individuals 
who were eligible to vote did not do so. This turnout rate is similar to those in other recent national elections and much higher than those without a presidential race. Many investigators have attempted to identify the traits that characterize non-voters in the United States $[1,17]$ but none of these efforts analyzes the potentially crucial role of variation in neuroendocrine function.

The HPA axis is central for regulating a variety of adaptive physiological and psychological processes, including energy balance, coping with short-term stressors, and mediating psychosocial responses to these stressors. It is well-established that there is considerable inter-individual variation in both HPA set points (i.e., baseline levels of glucocorticoids) and HPA reactivity to stressors, and that individuals exhibiting atypical patterns of basal and stress-induced cortisol levels may be at risk for negative health consequences [43]. Given that political activities are well-known to elevate stress, particularly in "winner-take-all" systems such as the United States, it seems likely that those individuals with low stress thresholds (high baseline levels of glucocorticoids) might be relatively averse to participating in contested elections. The existing empirical evidence implicating HPA function in social behavior, cognitive processing and decision-making, and socioemotional responsiveness, all of which are part of individual-level political activity, buttresses these expectations. In addition, like HPA function, participation in electoral politics is also relatively stable throughout an individual's lifetime [16,17,44], making it even more likely that HPA activity and political activity are correlated.

Our findings are strongly supportive of these theoretical expectations in that individual-level variation in HPA axis activity correlates inversely with political involvement. Moreover, the situations in which a correlation is NOT observed are also instructive. For example, the best predictor of political involvement from among the CORT measures is not the degree to which individuals' CORT responds to a stressful social situation (the TSST) but rather afternoon CORT measured prior to initiation of the stressor, suggesting baseline levels rather than changes in response to a stressor are most relevant in accounting for variation in voting behavior.

Another aspect of our results that is particularly intriguing is that variation in nonvoting political participation is not explained by differences in baseline CORT, while variation in voting behavior is significantly predicted by this HPA parameter. This dissociation may be attributed to the fact that nonvoting political activity, such as participating in a political rally, tends to occur in the context of like-minded social partners with politically-compatible beliefs, while voting behavior typically involves decision-making and emotional conflict among potentially politically incompatible alternatives [45] that individuals with elevated afternoon HPA function may find less palatable. The effect size for adding afternoon baseline CORT to the hierarchical regression model (Cohen' $f^{2}=0.07$ ) is small to modest [42], yet it accounts for significant variance in voting frequency. Importantly, this relationship holds even when controlling for the demographic variables that have previously been demonstrated to profoundly influence levels of political activity $[1,2,6]$. In fact, the CORT-voting relationship we demonstrate in this study is one of the few reported in the realm of individual-level politics in which neither predictor (baseline CORT) nor criterion variable (actual voting behavior) is based on a self-report. Over-reporting of personal 
involvement in a number of social and political activities is a common finding [46-48], and our results suggest that variation in self-reported activities may not reflect underlying physiological differences, whereas variation in actual behavioral measures are associated with important differences in HPA function.

The finding that religious participation is not strongly predicted by baseline CORT is potentially supportive of the line of thought holding that participation in social activities with like-minded individuals is less likely to be constrained by high HPA activity. Both attending religious services and attending political rallies are characterized by the convergence of like-minded and socially cohesive groups [49]. Conviction and cohesiveness are features that religious participation clearly shares with involvement in political campaigns but voting in competitive elections is different and this may be why baseline CORT levels correlate with voting but not with attendance at religious services or political campaign rallies. This account is speculative but consistent with the empirical results reported here.

Participants in our study provided samples late in the afternoon, a time at which CORT levels are typically low, relative to earlier phases of the waking circadian cycle. There is considerable evidence that elevated CORT, particularly in the afternoon phase of the circadian cycle, is associated with socially-avoidant behavioral phenotypes [29,30]. Further, elevated afternoon CORT is also linked with attachment-related anxiety [50], enhanced memory for fear-related stimuli [51], and insensitivity to punishment in a laboratory gambling task [28]. Finally, a recent meta-analysis revealed that while most parameters of HPA function did not differ markedly between patients with major depressive disorder (MDD) and nondepressed controls, the one feature that distinguished these populations was elevated afternoon baseline CORT in patients with MDD [32]. Thus, elevated CORT later in the day appears to be associated with a host of social, affective, and cognitive traits that may contribute to variation in the tendency of individuals to participate in something as stressful as electoral politics.

Three approaches that would allow future research to shed light on these matters are: 1) determining the association of variations in CORT and a variety of other life activities, 2) replicating this research in non-U.S. political systems where levels of participation in voting are higher than in the U.S., and 3) extending the political variables to include extremity of beliefs. Such investigations would make it possible to assess whether high CORT is negatively associated with social behaviors other than politics (and religion), whether the negative association between baseline CORT and voting frequency is unique to the adversarial politics of the United States or is also apparent in more consociational politics [52], whether high CORT individuals might be more likely to cast ballots through mechanisms like absentee ballots [33], and whether high CORT individuals are more or less likely to hold extreme political beliefs. As Fiorina [53] points out, politics seems to be dominated by those who are not in the ideological middle. Perhaps low CORT individuals tend to be those who drive politics away from the ideological middle — a middle that would be more vocal and involved were it not for certain physiologically-instantiated aversions. 
The HPA axis is central for regulating a variety of adaptive physiological and psychological processes, including energy balance, coping with short-term stressors, and mediating psychosocial responses to these stressors. It is well-established that there is considerable inter-individual variation in both HPA set points (i.e., baseline levels of glucocorticoids) and HPA reactivity to stressors, and that individuals exhibiting atypical patterns of basal and stress-induced cortisol levels may be at risk for negative health consequences [43]. Like HPA function, participation in electoral politics is also relatively stable throughout an individual's lifetime $[16,17,44]$. Our results showing a significant association between HPA function and voting behavior suggest that underlying biological predispositions can account for some of the variation in political involvement. The empirical evidence implicating HPA function in social behavior, cognitive processing and decision-making, and socioemotional responsiveness, all of which are part of individual-level political activity, suggests that political behavior, particularly the very act of voting, can be fruitfully approached from a biological perspective.

\section{Supplementary Material}

Refer to Web version on PubMed Central for supplementary material.

\section{Acknowledgments}

We thank the faculty of the UNO Political Science department for helpful comments on previous versions of this manuscript. Shelton Hendricks provided useful feedback and insight on many aspects of this project. This project was supported by NSF (BCS0826828), and UNO's Endocrine Bioservices Laboratory was supported in part by NIH (HD042882) and the Nebraska Foundation. The funding sources had no involvement in the design, execution, analysis, or decision to submit this article for publication.

\section{References}

1. Verba, S.; Schlozman, KL.; Brady, HE. Voice and equality: Civic voluntarism in American politics. Cambridge, MA: Harvard Univ Pr; 1995.

2. Caprara GV, Schwartz S, Capanna C, Vecchione M, Barbaranelli C. Personality and politics: Values, traits, and political choice. Polit Psychol. 2006; 27:1-28.

3. Fowler JH, Baker LA, Dawes CT. Genetic variation in political participation. Am Polit Sci Rev. 2008; 102:233-48.

4. Fowler JH, Dawes CT. Two genes predict voter turnout. J Polit. 2008; 70:579-94.

5. Gerber AS, Huber GA, Doherty D, Dowling CM, Ha SE. Personality and political attitudes: Relationships across issue domains and political contexts. Am Polit Sci Rev. 2010; 104:111-33.

6. Mondak JJ, Hibbing MV, Canache D, Seligson MA, Anderson MR. Personality and civic engagement: An integrative framework for the study of trait effects on political behavior. Am Polit Sci Rev. 2010; 104:85-110.

7. Alford JR, Funk CL, Hibbing JR. Are political orientations genetically transmitted. Am Polit Sci Rev. 2005; 99:153-67.

8. Hatemi PK, Medland SE, Morley KI, Heath AC, Martin NG. The genetics of voting: An Australian twin study. Behav Genet. 2007; 37:435-48. [PubMed: 17221311]

9. Kanai R, Feilden T, Firth C, Rees G. Political orientations are correlated with brain structure in young adults. Curr Biol. 2011; 21:677-80. [PubMed: 21474316]

10. Amodio DM, Jost JT, Master SL, Yee CM. Neurocognitive correlates of liberalism and conservatism. Nat Neurosci. 2007; 10:1246-7. [PubMed: 17828253]

11. Oxley DR, Smith KB, Alford JR, Hibbing MV, Miller JL, Scalora M, et al. Political attitudes vary with physiological traits. Science. 2008; 321:1667. [PubMed: 18801995] 
12. Dodd MD, Balzer A, Jacobs CM, Gruszczynski MW, Smith KB, Hibbing JR. The political left rolls with the good and the political right confronts the bad: connecting physiology and cognition to preferences. Philos Trans R Soc B Biol Sci. 2012; 367:640-9.

13. Putnam, RD. Bowling alone: America's declining social capital. New York: Simon \& Schuster; 2000.

14. Gerber AS, Green DP, Larimer CW. Social pressure and voter turnout: Evidence from a large-scale field experiment. Am Polit Sci Rev. 2008; 102:33-48.

15. Green, DP.; Gerber, AS. Get out the vote: How to increase voter turnout. Washington DC: Brookings Inst Pr; 2008.

16. Green DP, Shachar R. Habit formation and political behaviour: Evidence of consuetude in voter turnout. Br J Polit Sci. 2000; 30:561-73.

17. Plutzer E. Becoming a habitual voter: Inertia, resources, and growth in young adulthood. Am Polit Sci Rev. 2002; 96:41-56.

18. Sears DO, Funk CL. Evidence of the long-term persistence of adults' political predispositions. J Polit. 1999; 61:1-28.

19. Prior M. You've either got it or you don't? The stability of political interest over the life cycle. J Polit. 2010; 72:747-66.

20. Leighley JE, Nagler J. Socioeconomic class bias in turnout, 1964-1988: The voters remain the same. Am Polit Sci Rev. 1992:725-36.

21. Huizenga NATM, Koper JW, de Lange P, Pols HAP, Stolk RP, Grobbee DE, et al. Interperson variability but intraperson stability of baseline plasma cortisol concentrations, and its relation to feedback sensitivity of the hypothalamo-pituitary-adrenal axis to a low dose of dexamethasone in elderly individuals. J Clin Endocrinol Metab. 1998; 83:47-54. [PubMed: 9435415]

22. Cohen S, Hamrick N. Stable individual differences in physiological response to stressors: implications for stress-elicited changes in immune related health. Brain Behav Immun. 2003; 17:407-14. [PubMed: 14583231]

23. Redei EE. Molecular genetics of the stress-responsive adrenocortical axis. Ann Med. 2008; 40:139-48. [PubMed: 18293144]

24. Uhart M, McCaul M, Oswald L, Choi L, Wand G. GABRA6 gene polymorphism and an attenuated stress response. Mol Psychiatry. 2004; 9:998-1006. [PubMed: 15197399]

25. Jabbi M, Korf J, Kema I, Hartman C, Van der Pompe G, Minderaa R, et al. Convergent genetic modulation of the endocrine stress response involves polymorphic variations of 5-HTT, COMT and MAOA. Mol Psychiatry. 2007; 12:483-90. [PubMed: 17453062]

26. Ellis BJ, Jackson JJ, Boyce WT. The stress response systems: Universality and adaptive individual differences. Dev Rev. 2006; 26:175-212.

27. Diorio J, Meaney MJ. Maternal programming of defensive responses through sustained effects on gene expression. J Psychiatry Neurosci. 2007; 32:275-84. [PubMed: 17653296]

28. Honk J, Schutter DJLG, Hermans EJ, Putman P. Low cortisol levels and the balance between punishment sensitivity and reward dependency. Neuroreport. 2003; 14:1993. [PubMed: 14561936]

29. Tse WS, Bond AJ. Relationship between baseline cortisol, social functioning and depression: a mediation analysis. Psychiatry Res. 2004; 126:197-201. [PubMed: 15157746]

30. Susman EJ, Dockray S, Schiefelbein VL, Herwehe S, Heaton JA, Dorn LD. Morningness/ eveningness, morning-to-afternoon cortisol ratio, and antisocial behavior problems during puberty. Dev Psychol. 2007; 43:811. [PubMed: 17605516]

31. Wedekind D, Bandelow B, Broocks A, Hajak G, Rüther E. Salivary, total plasma and plasma free cortisol in panic disorder. J Neural Transm. 2000; 107:831-7. [PubMed: 11005547]

32. Burke HM, Davis MC, Otte C, Mohr DC. Depression and cortisol responses to psychological stress: a meta-analysis. Psychoneuroendocrinology. 2005; 30:846-56. [PubMed: 15961250]

33. Waismel-Manor I, Ifergane G, Cohen H. When endocrinology and democracy collide: Emotions, cortisol and voting at national elections. Eur Neuropsychopharmacol. 2011; 21:789-95. [PubMed: 21482457] 
34. Stanton SJ, LaBar KS, Saini EK, Kuhn CM, Beehner JC. Stressful politics: voters' cortisol responses to the outcome of the 2008 United States Presidential election. Psychoneuroendocrinology. 2010; 35:768-74. [PubMed: 19962831]

35. Blanton H, Strauts E, Perez M. Partisan Identification as a Predictor of Cortisol Response to Election News. Polit Commun. 2012; 29:447-60.

36. Kirschbaum C, Pirke KM, Hellhammer DH. The "Trier Social Stress Test" - a tool for investigating psychobiological stress responses in a laboratory setting. Neuropsychobiology. 1993; 28:76-81. [PubMed: 8255414]

37. Dickerson SS, Kemeny ME. Acute stressors and cortisol responses: a theoretical integration and synthesis of laboratory research. Psychol Bull. 2004; 130:355-91. [PubMed: 15122924]

38. Von Dawans B, Kirschbaum C, Heinrichs M. The Trier Social Stress Test for Groups (TSST-G): A new research tool for controlled simultaneous social stress exposure in a group format. Psychoneuroendocrinology. 2011; 36:514-22. [PubMed: 20843608]

39. Smith TE, French JA. Psychosocial stress and urinary cortisol excretion in marmoset monkeys. Physiol Behav. 1997; 62:225-32. [PubMed: 9251962]

40. Minton ME, Hertzog M, Barron CR, French JA, Reiter-Palmon R. The First Anniversary: Stress, Well-Being, and Optimism in Older Widows. West J Nurs Res. 2009; 31:1035-56. [PubMed: 20008309]

41. Pruessner JC, Kirschbaum C, Meinlschmid G, Hellhammer DH. Two formulas for computation of the area under the curve represent measures of total hormone concentration versus time-dependent change. Psychoneuroendocrinology. 2003; 28:916-31. [PubMed: 12892658]

42. Cohen J. A power primer. Psychol Bull. 1992; 112:155-9. [PubMed: 19565683]

43. Juster R-P, Bizik G, Picard M, Arsenault-Lapierre G, Sindi S, Trepanier L, et al. A transdisciplinary perspective of chronic stress in relation to psychopathology throughout life span development. Dev Psychopathol. 2011; 23:725-6. [PubMed: 21756430]

44. Gerber AS, Green DP, Shachar R. Voting may be habit-forming: evidence from a randomized field experiment. Am J Polit Sci. 2003; 47:540-50.

45. Verba, S.; Nie, NH. Participation in America: Social equality and political democracy. New York: Harper \& Row; 1972.

46. Brenner PS. Identity importance and the overreporting of religious service attendance: Multiple imputation of religious attendance using the American Time Use Study and the General Social Survey. J Sci Study Relig. 2011; 50:103-15.

47. Brenner PS. Testing the veracity of self-reported religious practice in the Muslim world. Soc Forces. 2014; 93:1009-37.

48. Brenner PS. Overreporting of voting participation as a function of identity. Soc Sci J. 2012; 49:421-9.

49. Galen LW, Kloet J. Personality and Social Integration Factors Distinguishing Nonreligious from Religious Groups: The Importance of Controlling for Attendance and Demographics. Arch Psychol Relig. 2011; 33:205-28.

50. Quirin M, Pruessner JC, Kuhl J. HPA system regulation and adult attachment anxiety: individual differences in reactive and awakening cortisol. Psychoneuroendocrinology. 2008; 33:581-90. [PubMed: 18329180]

51. Putman P, Van Honk J, Kessels RP, Mulder M, Koppeschaar HP. Salivary cortisol and short and long-term memory for emotional faces in healthy young women. Psychoneuroendocrinology. 2004; 29:953-60. [PubMed: 15177712]

52. Lijphart, A. Democracies: Patterns of Majoritarian and Consensus Government in Twenty-One Democracies. New Haven, CT: Yale University Press; 1984.

53. Fiorina, MP. Culture War? The Myth of a Polarized America. New York: Pearson Longman; 2005. 


\section{HIGHLIGHTS}

Participation in national elections in U.S. is low: $40-60 \%$ of voters participate

We measured actual voting behavior and nonvoting political activities

Variation in baseline cortisol (CORT) accounts for variance in voting behavior

CORT differences do not explain variation in other kinds of political involvement

First demonstration that actual electoral participation associated with physiology 


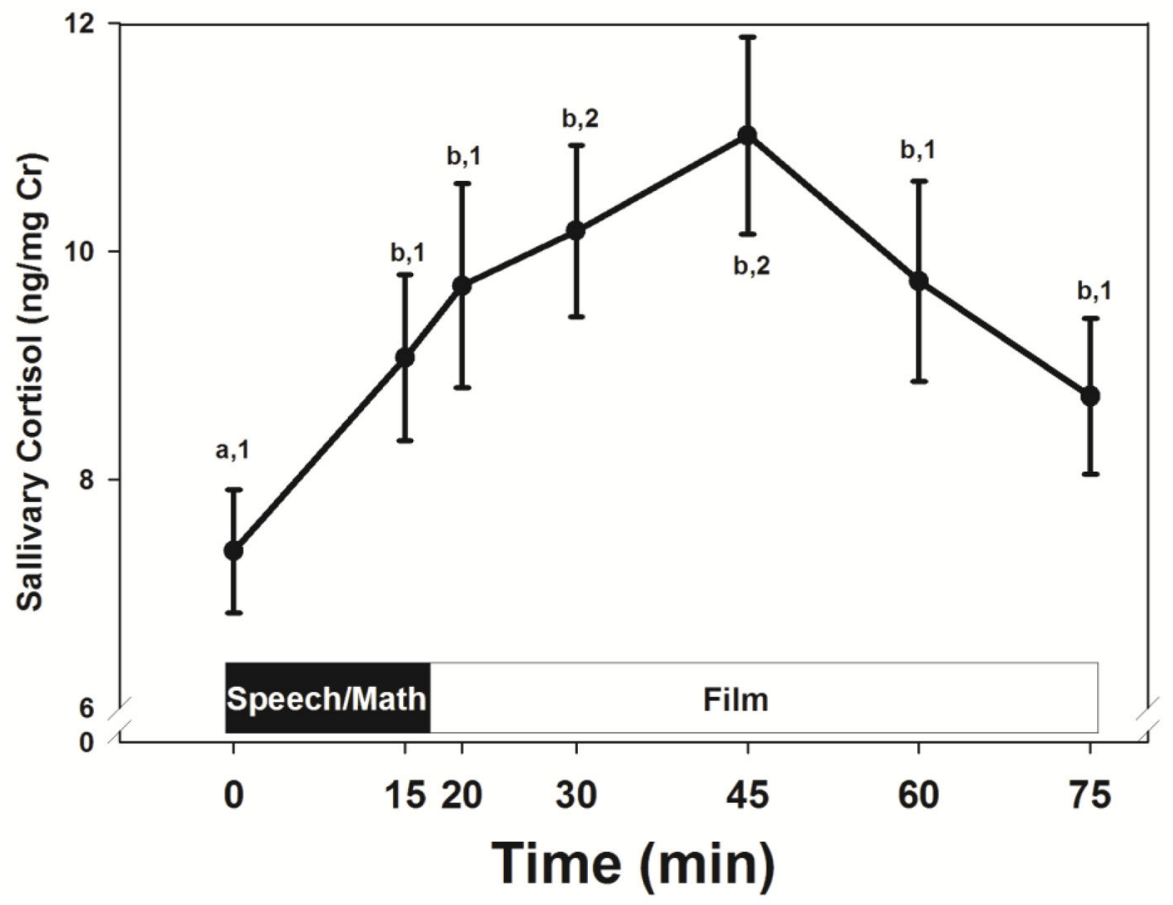

Figure 1.

Mean ( \pm s.e.m.) salivary CORT prior to, during and after social/evaluative stressor.

Different letter superscripts indicate means differ from baseline CORT; different numerical superscripts indicate means differ from 75-min salivary CORT $(\mathrm{p}<0.05)$. 


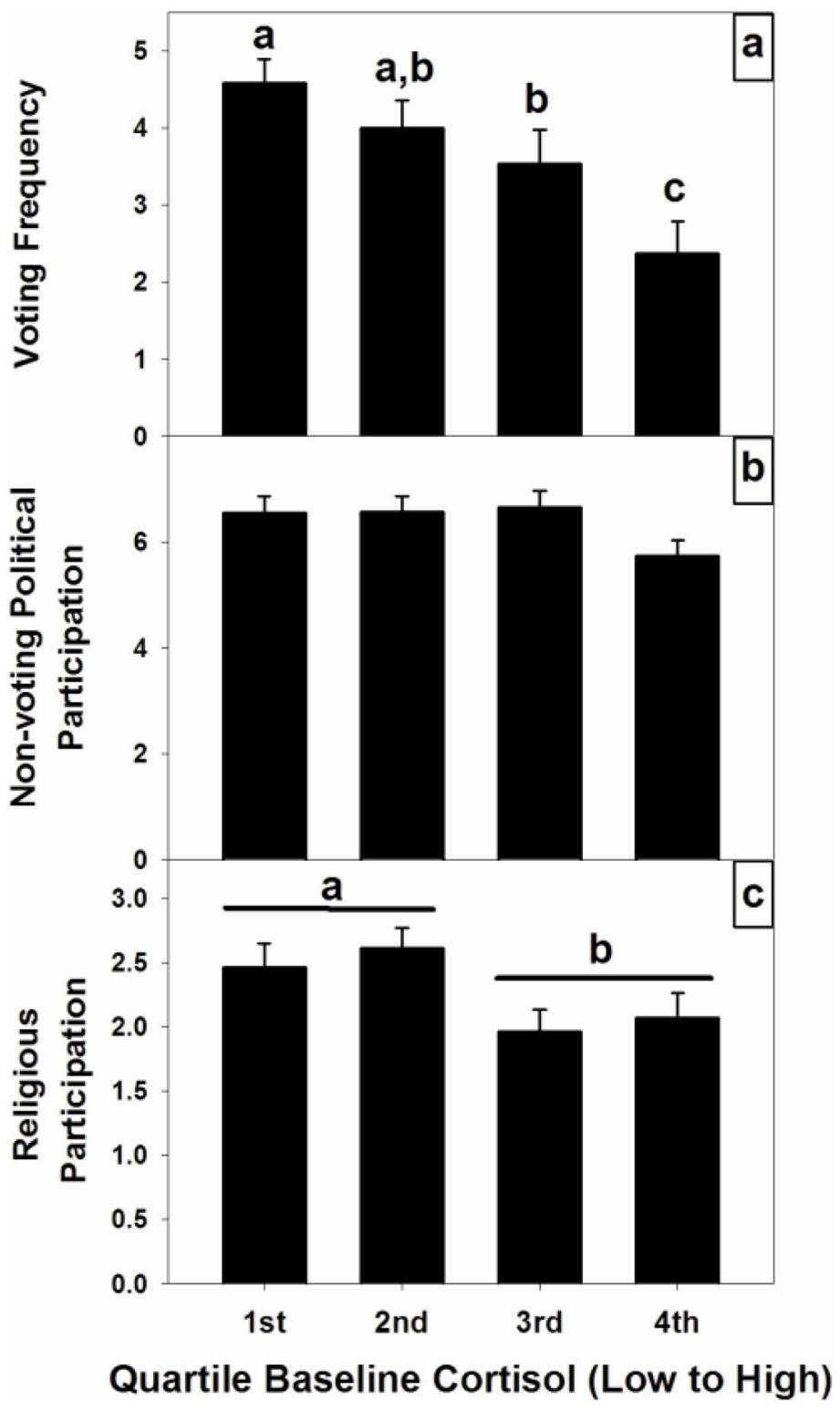

Figure 2.

Analysis of voting behavior as a function of quartile assignment of participants based on baseline CORT values. $\mathrm{a}=$ voting frequency; $\mathrm{b}=$ non-voting political participation; $\mathrm{c}=$ religious participation. Bars with differing letters are significantly different by Tukey's posthoc tests $\left(\mathrm{P}^{\prime} \mathrm{s}<0.05\right)$. N's $=26,26,26$, and 27 for $1^{\text {st }}$ through $4^{\text {th }}$ quartile of baseline CORT, respectively. 


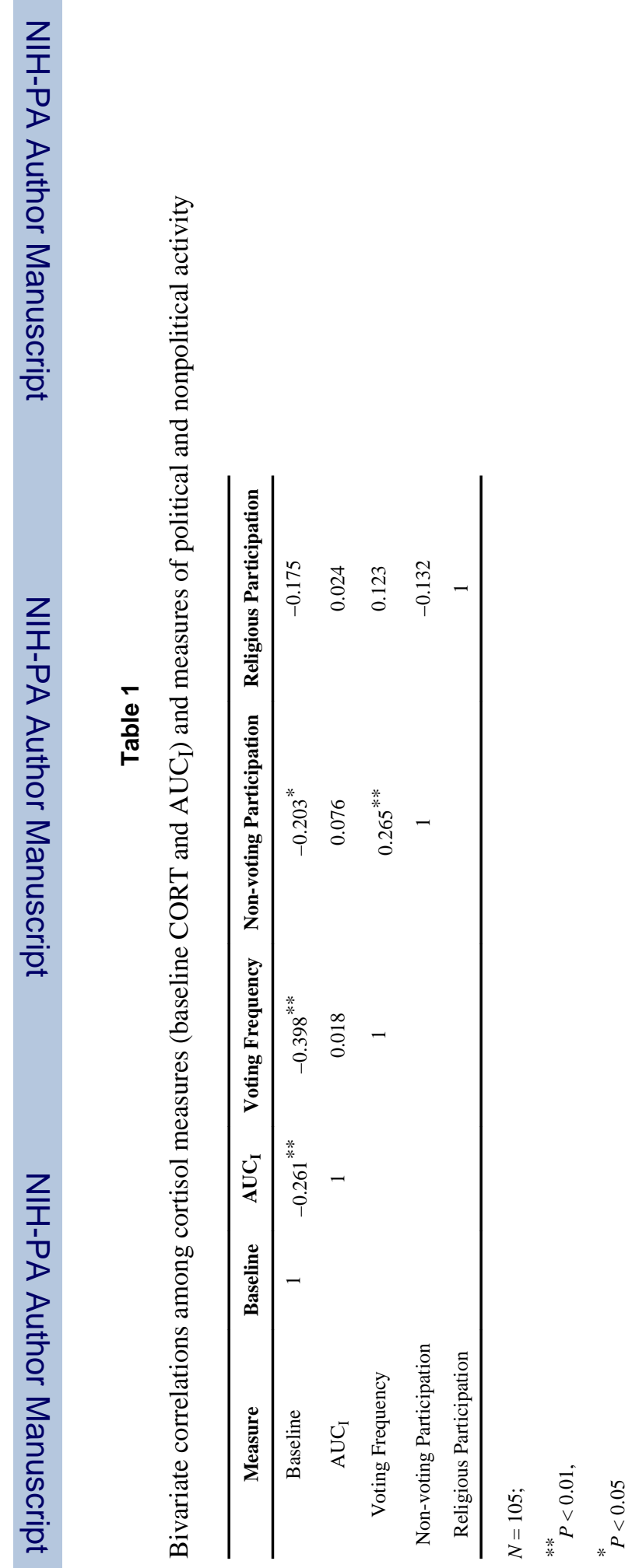

Physiol Behav. Author manuscript; available in PMC 2015 June 22. 


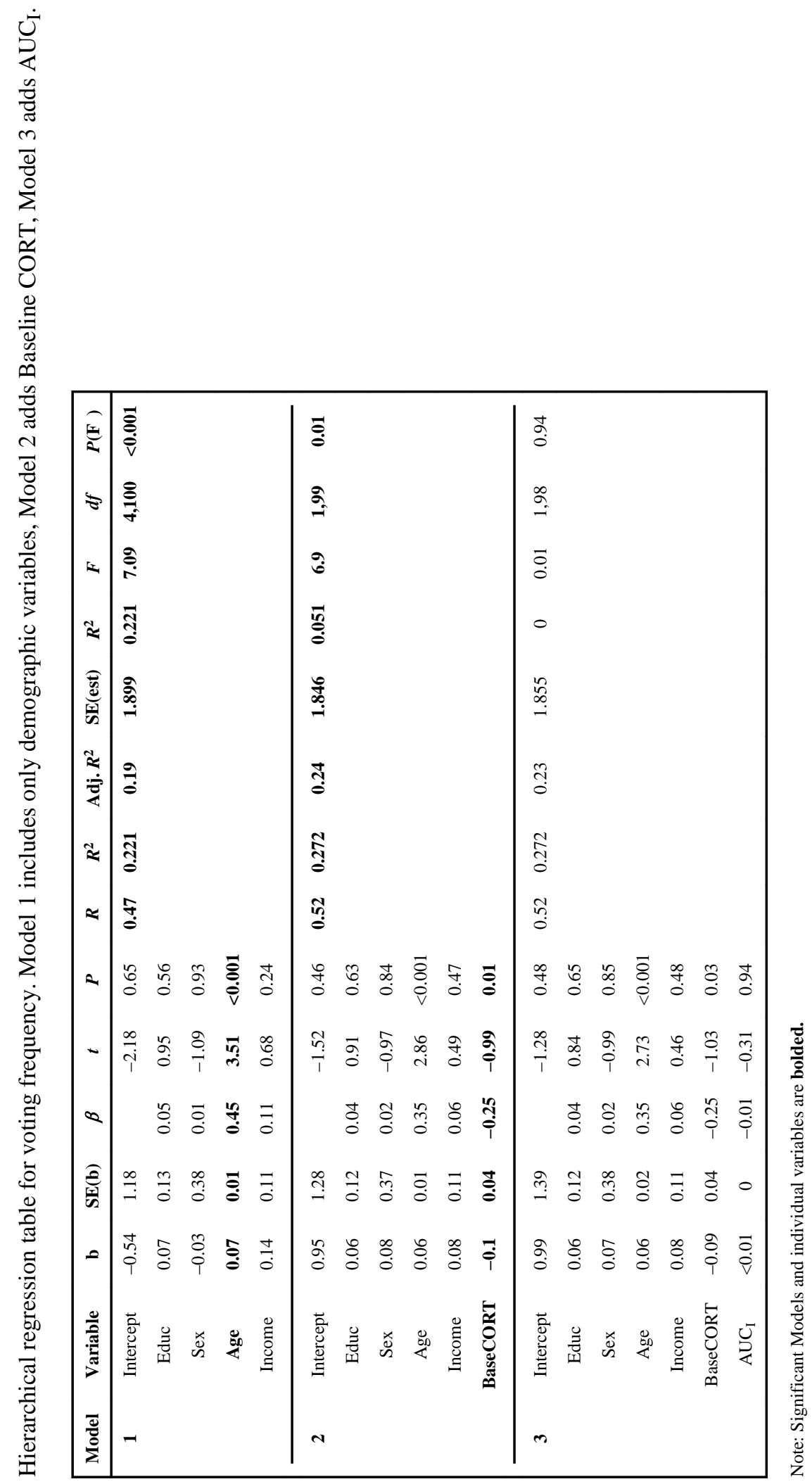


造

\begin{tabular}{|c|c|c|c|}
\hline 公 & 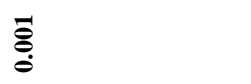 & $\stackrel{0}{\circ}$ & สุ \\
\hline 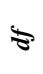 & $\stackrel{\Xi}{f}$ & $\stackrel{g}{=}$ & $\stackrel{\infty}{\stackrel{\sim}{二}}$ \\
\hline$\Delta$ & $\hat{j}$ & 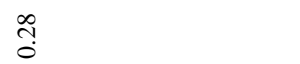 & $\stackrel{n}{n}$ \\
\hline$\underset{\mathbb{Z}}{\approx}$ & $\stackrel{8}{\dddot{0}}$ & $\stackrel{\widetilde{c}}{\circ}$ & $\stackrel{m}{0}$ \\
\hline 施 & $\stackrel{\infty}{\infty}$ & $\begin{array}{l}\infty \\
\infty \\
\infty \\
\infty\end{array}$ & $\begin{array}{l}\infty \\
\infty \\
\infty \\
\infty\end{array}$ \\
\hline$\underset{z}{\sharp}$ & $\stackrel{9}{0}$ & $\stackrel{0}{0}$ & $\stackrel{m}{0}$ \\
\hline$\approx$ & 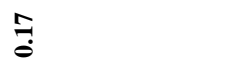 & 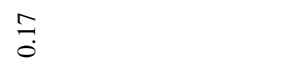 & $\frac{\infty}{0}$ \\
\hline$\approx$ & $\stackrel{f}{g}$ & J. & $\stackrel{f}{0}$ \\
\hline 2 & 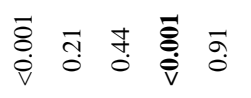 & 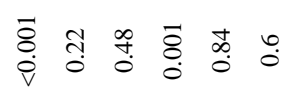 & 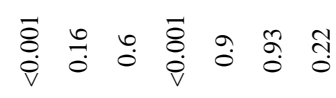 \\
\hline- & 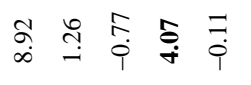 & 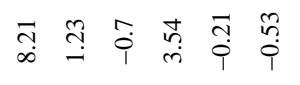 & 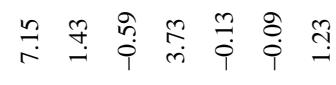 \\
\hline$\infty$ & 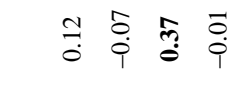 & 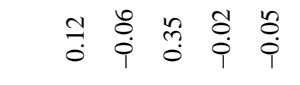 & 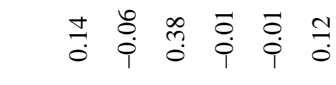 \\
\hline 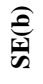 & 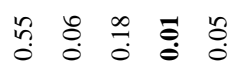 & 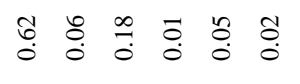 & 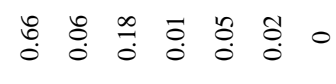 \\
\hline$=$ & 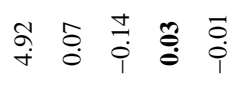 & 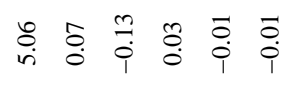 & 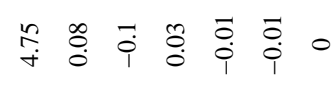 \\
\hline 离 & 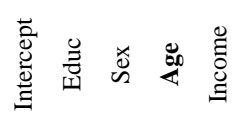 & 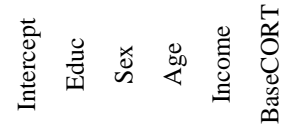 & 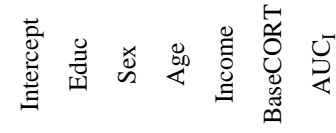 \\
\hline$\sum_{\bar{z}}^{\bar{\Xi}}$ & - & N & \\
\hline
\end{tabular}

